\title{
Intracorneal Ring Segment Implantation in the Management of Keratoconus: An Evidence- Based Approach
}

\author{
Dimitris Sakellaris · Miltos Balidis • Olga Gorou • Nora Szentmary • \\ Antonios Alexoudis · Matthias C. Grieshaber · Despoina Sagri • \\ Hendrik Scholl · Zisis Gatzioufas
}

Received: May 15, 2019

(C) The Author(s) 2019

\begin{abstract}
Intracorneal ring segment (ICRS) implantation represents a modern, minimally invasive, surgical option for visual improvement in patients with keratoconus. ICRS modify the corneal geometry in a manner that enhances its refractive properties and thereby, they improve visual acuity. It is well-documented that implantation of ICRS decreases the keratometric readings, spherical equivalent and cylinder, reduces highorder aberrations and improves uncorrected distance visual acuity (UDVA) and best-corrected distance visual acuity (BCDVA) in patients with keratoconus. Success rate after ICRS implantation is high, depending on
\end{abstract}

Enhanced Digital Features To view enhanced digital features for this article go to https://doi.org/10.6084/ m9.figshare.9746591.

D. Sakellaris · M. Balidis · O. Gorou · D. Sagri Ophthalmica Institute, Thessaloniki, Greece

\section{N. Szentmary}

Department of Ophthalmology, University Clinic

Saarland, Homburg, Saarland, Germany

N. Szentmary

Department of Ophthalmology, Semmelweis

University, Budapest, Hungary

A. Alexoudis - M. C. Grieshaber · H. Scholl

Z. Gatzioufas $(\bowtie)$

Department of Ophthalmology, University Hospital

Basel, Basel, Switzerland

e-mail: zisisg@hotmail.com appropriate patient selection and adherence to suitable implantation nomograms, and most important, the overall complication rate is very low. This review is summarizing current indications/contra-indications for ICRS implantation, implantation techniques, clinical outcomes and potential complications, shedding light on myths and realities related to this innovative surgical option.

Keywords: Implantation; Intracorneal ring; Keratoconus

\section{INTRODUCTION}

Keratoconus is a progressive, non-inflammatory cornealectatic disease characterized by corneal steepening and thinning, generating high degree of myopia and irregular astigmatism, thereby severely impairing visual acuity [1].Today, there are several therapeutic options to achieve visual rehabilitation in keratoconus, such as rigid gas-permeable contact lenses,intracorneal ring segment (ICRS) implantation, corneal surface ablation combined with corneal crosslinking (CXL), implantation of toricphakic intraocular lenses and, finally, lamellar or penetrating keratoplasty [2-6].

Intracorneal ring segments (ICRS) are small PMMA(polymethyl methacrylate) devices, which are implanted into the cornea aiming to 
alter its geometry and improve its refractive properties and patient's visual acuity. Colin introduced the use of ICRS implantation for the management of keratoconus in 2000 [4].Nevertheless, Reynolds was the first to implant a $360^{\circ}$ intracorneal ring for the management of myopia in 1978 [7].

Since then, many different types of ICRS with variable thickness, geometries and diameters have been developed and used for restoring visual acuity in patients with keratoconus. The implantation of ICRS was initially mechanically, but over the last years femtosecond laserassisted procedures gained increasing significance and currently are gradually replacing the conventional mechanical technique. Nowadays, there are implantation nomograms, most of them offered by the ICRS manufactures, indicating the appropriate ring segment characteristics and suggesting the most suitable parameters for ICRS implantation for each individual case. There are also certain indications and contraindications regarding the patient selection which maximize the safety and efficacy of the treatment.

The purpose of the present review article is to provide an update on the current status of ICRS implantation as a modern therapeutic option in the visual rehabilitation of patients with keratoconus. This article is based on previously conducted studies and does not contain any studies with human participants or animals performed by any of the authors.

\section{MECHANISM OF ACTION}

ICRS act as spacer elements between the collagen fibres of the corneal tissue [8].Thus, ICRS induce an arc-shortening effect of the corneal geometry that flattens the central area of the corneal tissue. Theoretical models based on finite element analysis, have proven that the flattening observed after ICRS implantation is directly proportional to the thickness of the implanted segment and inversely proportional to the corneal diameter of the implantation site; this means that the thicker and the smaller the ICRS diameter, the higher the corneal flattening effect [9]. However, this theoretical analysis is valid for normal corneas with orthogonal collagen fiber architecture and not for keratoconic corneas with an abnormal arrangement of the collagen fibers, which increases the unpredictability of the ICRS effect [10]. Another theory that may explain the mechanism of action of the ICRS is the "thickness law" proposed by Barraquer, stating that flattening of the cornea occurs when tissue is added to the periphery of the cornea or tissue is removed from the corneal center [11].

\section{TYPES OF INTRACORNEAL RING SEGMENTS}

Nowadays, different types of ICRS are commercially available, and the most commonly used in the clinical practice are the Keraring (Mediphacos), the Intacs (Addition technologies), the Ferrara rings (AJL Ophthalmic), the Intacs SK(Addition technologies), and the Myoring (Dioptex). The Myoringis the only one with a $360^{\circ}$ design and is implanted into a corneal stromal pocket. Daxer et al. favours that kind of design and technique, as ICRS with arc smaller than $360^{\circ}$ are biomechanically neutral. Myoring strengthens and stabilizes the cornea considerably making the combination of CXL no longer necessary in progressive keratoconus [12].However, there are preliminary data of at least one study showing that Intacs may also have corneal stabilizing effect, although it is inferior to CXL-related biomechanical strengthening (unpublished data).

\section{INDICATIONS}

Patient selection is of paramount importance in ICRS implantation. Full ophthalmic examination should be performed including: (1) uncorrected and corrected visual acuity, (2) corneal topography and corneal aberrometry, (3) corneal pachymetry, preferably in form of a corneal pachymetric map aiming to assess the corneal thickness in the area of ICRS implantation and (4) corneal biomechanical analysis, with ocular response analyzer (ORA) or Corvis ST. Contact lenses discontinuation at least 1 week prior to 
the examination for soft contact lenses and for 2 weeks for rigid contact lenses, is necessary for reliable corneal measurements.

Good candidates for ICRS implantation are patients with keratoconus who fulfil most of the following criteria [13-15].

- Age $>18$ years

- Contact lens intolerance

- Corrected distance visual acuity $<0.6$ on the decimal scale.

- Corneal pachymetry $>400$ microns in the site of the corneal tunnel (depending on the thickness of ICRS to be implanted).

- Absence of central corneal scarring.

- Alignment of refractive and keratometric axes. The flattest meridian of the cornea (K1) should be aligned with the refractive cylinder axis (expressed as a negative value). When the meridian and the axis form an angle between 0 and $15^{\circ}$, they are considered properly aligned.

- No pregnancy for female patients.

\section{SURGICAL TECHNIQUES}

ICRS surgical procedure involves the insertion of the ring segments into the prior performed corneal channels or tunnels of deep corneal stroma. Two different methods have been described to create these tunnels: mechanical and femtosecond laser assisted [16, 17]. The two techniques are differentiated by the equipment used to create the intracorneal space for the implants. Both of them are typically performed under topical anesthesia.

The mechanical technique demands high surgical skills. Marking the pupil or geometrical centre of the cornea is mandatory to localize the site of the incision and the centre of the intrastromal dissection. Then, a $1 \mathrm{~mm}$ radial incision is performed, at the depth of $70-80 \%$ corneal thickness with a calibrated diamond knife. At the base of the incision pocketing dissectors are introduced on each side to form corneal intrastromal tunnels. A semi-automated vacuum-centering guide is placed along with the reference point on the corneal surface, at the limbus. Tunnels are created under vacuum, using two semicircular dissectors (corneal separators), and by advancing them steadily and rotationally into the lamellar pockets (clockwise and counterclockwise dissection). Once this step is completed, ending with tunnels in the desired directions and diameter, the surgeon removes the suction and inserts the implants into each ostia of the channels.

The femtosecond laser assisted method, requires the use of an infrared laser beam to create intrastromal cavitations and eventually a dissection plane at the desired depth through the photodisruption process. Similar to the manual approach, pupil centre is marked as a reference point, corneal thickness is measured at the site of implantation and the femtosecond laser docking system is adjusted. The laser creates an entry cut followed by tunnel dissection at about $70-80 \%$ of the corneal pachymetry. In the last step, the segments are inserted into each channel with the aid of special forceps [1823].Major advantages of femtosecond technique are the high level of precision and the minimal direct manipulation of the eye when creating the tunnels.

Numerous studies showed that both techniques were efficacious in achieving good visual and refractive results [18-22, 24-46] which were similar in cases with keratoconus and postLASIK ectasiain a short-term follow up [47].

\section{NOMOGRAMS: INCISION PLACEMENT/ICRS SELECTION}

Nomograms are clinical guidelines for surgeons to determine parameters important for the procedure success. These parameters for ICRS procedures include a number of the segment rings, their arc length and thickness as well as the location of insertion. Drawbacks of nomograms are their empirical character, based on (unpublished) clinical data, and their non-correspondence to an accurate mathematical model on the ICRS effect on the ectatic cornea [15]. Spherocylindrical refraction and topographic profile are rather subjective than objective variables in most nomograms [48].

Aiming for the implants to bisect the thinnest part of the cornea, several authors consider 
the steepest keratometric axis as the most suitable site to place the vertical incision $[26,49,50]$. This site proves to be temporal in most patients with oval and central cones [29-31, 51]. Others have demonstrated that the axis of coma aberration is their preferable guide reference for implantation. Also, best results for ICRS implantation were achieved when the difference between the refractive and topographic cylinder did not exceed $15^{\circ}$ of separation $[48,52,53]$.

Furthermore, the asymmetry of segments may provide more astigmatic effect. Therefore, in cases of central cones, using two symmetrical segment rings is likely to produce maximum flattening effect. In oval cones however, asymmetrical ring segments or even single ring segment placed inferiorly according to the topographic profile may induce greater regularization [15, 44, 48, 50].

In cases of post-LASIK ectasia, single inferior ring segment appears to be the best option. In patients with pellucid marginal degeneration though, the location of ICRS implantation is still debated. Some surgeons locate the implants in a way that the steepest part of the cornea is bisected, while others claim the temporal incision is the best option to place the two segments on both sides of the horizontal meridian $[50,54]$. Arc length and thickness of segments are two main variables for ICRS implantation. Surgeons have utilized $120^{\circ}$ arc length segment [31] or 2 segments of $160^{\circ}$ arc length at different thicknesses, depending on the targeted spherical equivalent and the severity of the disease (with good outcomes).Implanting two $160^{\circ}$ arc length segments of $200 \mu \mathrm{m}$ thickness will correct $-2 \mathrm{D}, 250 \mu \mathrm{m}-4 \mathrm{D}, 300 \mu \mathrm{m}-6 \mathrm{D}$, and $350 \mu \mathrm{m}$ most likely sufficient for $-8 \mathrm{D}$ correction [15, 20, 32, 55] The same nomogram was also implemented with good results with the use of one $120^{\circ}$ arc length segment [31].

For keratoconus, nomograms applied in a similar way. Two segments of $160^{\circ}$ arc length, with $150 \mu \mathrm{m}$ thickness for keratoconic cases of less than $-4 \mathrm{D}, 200 \mu \mathrm{m}$ for cases between -4.25 and $-6 \mathrm{D}, 250 \mu \mathrm{m}$ for -6.25 to $-8 \mathrm{D}$, $300 \mu \mathrm{m}$ for -8.25 to $-10 \mathrm{D}$, and $350 \mu \mathrm{m}$ for cases with more than $-10 \mathrm{D}$ [56]. Some manufacturers also propose to implant 2 segments of $160^{\circ}$ arc length selecting different distribution and thickness of each segment based on spherical equivalent and corneal topographic pattern [20].

A semi-automatic computational methodology has been presented in order to simulate the ICRS surgical operation and predict the postsurgical optical outcomes. Interestingly stromal depth insertion is the most effective parameter to alter corneal optics. ICRS inserted deep in the posterior stroma will prevent ectasia progression (relaxation of posterior surface), but will promote its growing if they are located in the anterior surface (increment of stress) [82].

\section{CLINICAL OUTCOMES}

Corneal changes induced by ICRS implantation are responsible for visual, refractive and keratometric improvement in different types of ectatic corneal disease [15, 23, 55, 57-59].

The majority of peer-reviewed scientific literature demonstrates a statistically significant central corneal flattening with ICRS implantation. $[15,19,20,24,25,31,49,55,56]$ This outcome is anticipated from the mechanisms of action of intracorneal ring segments. Rings as spacer elements between the bundles of corneal lamellae an expected mechanic effect of spacer elements between stromal collagen lamellae, producing an additive volume effect in the midperipheral cornea, which can be nicely demonstrated in Scheimpflug images [23, 60].

In most of the studies, ring segments implantation contributed a mean reduction of the $\mathrm{K}$ readings between 3 and $5 \mathrm{D}$, with an astigmatic reduction between 1.5 to 2.88 (although Zare et al. in a prospective study with intacs presented a mean reduction of $0.75 \mathrm{~d}$ ) $[15,24,27,52,55,56,61]$. However, most of the studies didn't present their results in accordance with the standards for reporting refractive surgery outcomes, specifically absolute power and defocus equivalent. In addition subjective refraction in keratoconic patients is highly unpredictable. In advanced keratoconus stages head posture is used to align visual axis and cone center. This will result in visual 
function improvement but inevitably alter refractive measurement.

Corrected visual acuity results showed a significant variation. Keratoconus stage, cone location and ICRS type are important parameters for this variability ranging from 2 lines of loss of corrected vision to an 8 lines gain $[15,23,48,58,59]$. ICRS implantation leads to an increase of both uncorrected and corrected visual acuity in patients with, which is attributed to a reduction of spherical equivalent and cylinder, and to an enhancement of visual quality by modifying corneal high order aberrations. Asymmetric aberrations (coma and coma-like) and especially those higher than $3.0 \mu \mathrm{m}$, are reduced after ICRS implantation $[15,46,48,61-65]$. Therefore, this surgical procedure has a significant impact on corneal irregularity, by regularizing the geometry of corneal tissue [48, 61, 66]. As a consequence, CVA is affected, with most of the cases experiencing a corresponding improvement observed in $70-80 \%$ of treated patients $[45,46,63,66,67]$.

However, research data demonstrated a significant correlation between specific preoperative factors and procedure's efficacy. Preoperative visual acuity seems to be a resilient prognostic factor, specifically for keratoconus $[48,61,68]$. Vega-Estrada et al. reported that poor preoperative visual acuity is a good prognostic factor for significant visual improvement whereas Alio et al. suggested that it is less likely to achieve significant visual improvement in advanced keratoconus (stage 4) Advanced keratoconus has also been linked to low predictability of the keratometric and visual outcomes after ICRS implantation. Furthermore, a better visual outcome is expected when there is alignment of the refractive and keratometric axis angle $<15^{\circ}$ ) $[23,48,61]$. There is also concern about the functional efficacy of these implants when induced in stiffer corneas, such as in age-related or cross-linking-induced corneal changes. Gatzioufas et al. [23] reviewed ICRS implantation in patient older than 40 years. They reported a significant spherical equivalent and corneal astigmatism reduction (7.2 $\mathrm{d}$ and and $1.8 \mathrm{~d}$ respectively). Hence the threshold for an optimum surgery outcome still seems to remain controversial. Similarly, the cone eccentricity does not seem to affect visual outcomes after Keraring implantation for keratoconus [60].

Improved contact lens tolerance has been demonstrated after ICRS implantation. This is an important beneficial outcome, considering those cases with postoperative residual refraction error that needs to be corrected [15, 26, 49].

Studies with 6- to 9-year follow up underlined safety and stability with preservation of the initial refractive effect, thus suggesting ICRS implantation as a therapeutic option to halt progressive keratoconus [57, 63, 69-73]. However, long-term regression of the achieved spherical correction is also reported, making stability a debatable issue $[15,28,31]$. This could be attributed to the natural course of the disease. Nevertheless, progression was not evaluated preoperatively in those studies. In contrast to cases with a stable form of the disease, those with a documented progressive pattern were not able to maintain the initial postoperative result after a long period of time $[48,66,74]$. Consequently, it has been suggested that these implants are incapable to arrest cone progression [15].

In cases with progressive keratoconus, an additive effect on refractive and keratometric values can be achieved with a combined therapeutic approach of CXL and ICRS. Such combined procedure assists in increasing biomechanical rigidity and stability of the cornea [48, 74-76].

ICRS implantation might always give rise to an unexpected refractive result, since the nature of an ectatic corneal disorder could be rather unpredictable. Nevertheless, it is a surgical technique with documented successful visual outcomes and with the advantage of reversibility, as the visual and refractive measures are able to return to the baseline preoperative ones after the explantation of the segments.

\section{COMPLICATIONS}

The insertion of ICRS presents with positive results and seems minimally invasive. Nevertheless, it does not lack complications, either intraoperative or postoperative with both the 
manual and the femtosecond laser-assisted technique of insertion.

The introduction of the femtosecond laser assisted microkeratome revolutionized corneal surgery including the insertion of ICRS offering more precise and predictable size and depth of the intrastromal channels. Intraoperative complications were mainly related to the mechanical way of channel creation and include epithelial defects at the site of the keratotomy, incomplete channel formation and extension of the incision towards the central visual axis or towards the limbus.

Another type of complications of ICRS are position related such as asymmetrical positioning, and superficial placement of the ring segments due to inadequate channel depth and uneven placement, with superficial placement of the one end and deep placement of the other of the ring segments [34, 58]. More severe intraoperative complications are anterior chamber perforation due to very deep channel dissection or anterior Bowman's layer perforation due to superficial channel dissection $[19,58]$.

It is common sense to believe that the rate of complications would be higher with the use of a mechanical microkeratome for the creation of the channels/pockets compared to the use of femtosecond laser. However, the report by Ferrer et al. showed that there were more complications postoperatively and the rate of ICRS explantation higher in cases where channels were created by femtosecond than mechanically [59].

Postoperatively, a common complication is migration of the segment along the channel which is easily prevented by placing a suture at the incision. Other postoperative complications are epithelial plug formation at the site of the incision, corneal haze, deposits across the channel consisted of fatty acids and neovascularisation at the site of the incision or along the channel and persistent incisional gapping. The combination of superficial channel formation and segment migration can lead to segment extrusion with subsequent need for explantation, which is one of the most common postoperative complication [77-79].
A more serious postoperative complication is infectious keratitis along the channel and corneal melting probably related to superficial placement of the rings [69].

Other rare complications include night halos, chronic pain caused bydirect contact between the segment and a corneal nerve, focal edema, persistent inflammation, persistent fluctuation of vision, intraocular inflammation, photophobia and loss of uncorrected and bestcorrected visual acuity [80].

The main advantage of the insertion of ICRS for treating keratoconus and ectasia is the reversibility and the very low risk of compromising visual acuity [80]. ICRS implantation might always give rise to an unexpected refractive result, since the nature of an ectatic corneal disorder is poorly predictable. Nevertheless, ICRS is a surgical technique with well-documented successful visual outcomes and the advantage of reversibility, as the visual and refractive measures are able to return to the baseline after removing the segments $[77,80,81]$.

\section{ACKNOWLEDGEMENTS}

This supplement was not sponsored by outside commercial interests.

Funding. No funding or sponsorship was received for this study or publication of this article.

Authorship. All named authors meet the international Committee of Medical Journal Editors (ICMJE) criteria for authorship for this article, take responsibility for the integrity of the work as a whole, and have given their approval for this version to be published.

Disclosures. Dimitris Sakellaris, Miltos Balidis, Olga Gorou, Nora Szentmary, Antonios Alexoudis, Matthias C. Grieshaber, Despoina Sagri and Zisis Gatzioufas have nothing to declare. Dr. Hendrik Scholl is supported by the Foundation Fighting Blindness Clinical Research Institute (FFB CRI); Shulsky 
Foundation, New York, NY; National Centre of Competence in Research (NCCR) Molecular Systems Engineering (University of Basel and ETH Zürich), Swiss National Science Foundation, Wellcome Trust. Dr. Scholl is a paid consultant of the following entities: Boehringer Ingelheim Pharma GmbH \& Co. KG; Gerson Lehrman Group; Guidepoint. Dr. Scholl is member of the Scientific Advisory Board of the Astellas Institute for Regenerative Medicine; Gensight Biologics; Intellia Therapeutics, Inc.; Ionis Pharmaceuticals, Inc.; ReNeuron Group Plc/Ora Inc.; Pharma Research \& Early Development (pRED) of F. Hoffmann-La Roche Ltd; and Vision Medicines, Inc. Dr. Scholl is member of the Data Monitoring and Safety Board/Committee of the following entities: Genentech Inc./F. Hoffmann-La Roche Ltd; and ReNeuron Group Plc/Ora Inc. Dr. Scholl is member of the Steering Committee of the following entities: Novo Nordisk (FOCUS trial). Dr. Scholl is codirector of the Institute of Molecular and Clinical Ophthalmology Basel (IOB) which is constituted as a non-profit foundation and receives funding from the University of Basel, the University Hospital Basel, Novartis, and the government of Basel-Stadt. These arrangements have been reviewed and approved by the Johns Hopkins University in accordance with its conflict of interest policies. Johns Hopkins University and Bayer Pharma AG have an active research collaboration and option agreement. These arrangements have also been reviewed and approved by the University of Basel (Universitätsspital Basel, USB) in accordance with its conflict of interest policies. Dr. Hendrik Scholl is principal investigator of grants at the USB sponsored by the following entity: Acucela Inc.; Aegerion Pharmaceuticals (Novelion Therapeutics); Kinarus AG; NightstaRx Ltd.; Ophthotech Corporation; Spark Therapeutics England, Ltd. Grants at USB are negotiated and administered by the institution (USB) which receives them on its proper accounts. Individual investigators who participate in the sponsored project(s) are not directly compensated by the sponsor but may receive salary or other support from the institution to support their effort on the project(s).
Compliance with Ethics Guidelines. This article is based on previously conducted studies and does not contain any studies with human participants or animals performed by any of the authors.

Open Access. This article is distributed under the terms of the Creative Commons Attribution-NonCommercial 4.0 International License (http://creativecommons.org/licenses/ by-nc/4.0/), which permits any noncommercial use, distribution, and reproduction in any medium, provided you give appropriate credit to the original author(s) and the source, provide a link to the Creative Commons license, and indicate if changes were made.

\section{REFERENCES}

1. Rabinowitz YS. Keratoconus. Surv Ophthalmol. 1998;42:297-319.

2. Barnett M, Mannis MJ. Contact lenses in the management of keratoconus. Cornea. 2011;30:1510-6.

3. Vega-Estrada A, Alió JL, Plaza Puche AB, et al. Outcomes of a new microwave procedure followed by accelerated cross-linking for the treatment of keratoconus: a pilot study. J Refract Surg. 2012;28:787-93.

4. Colin J, Cochener B, Savary G, et al. Correcting keratoconus with intracorneal rings. J Cataract Refract Surg. 2000;26:1117-22.

5. Snibson GR. Collagen cross-linking: a new treatment paradigm in corneal disease-a review. Clin ExperimentOphthalmol. 2010;38:141-53.

6. Busin M, Scorcia V, Zambianchi L, et al. Outcomes from a modified microkeratome-assisted lamellar keratoplasty for keratoconus. Arch Ophthalmol. 2012;130:776-82.

7. Burris TE. Intrastromal corneal ring technology: results and indications. Curr Opin Ophthal Mol. 1998;9:9-14.

8. Silvestrini T, Mathis M, Loomas B, et al. A geometric model to predict the change in corneal curvature from the intrastromal corneal ring (ICR). Invest Ophthalmol Vis Sci. 1994;35:2023.

9. Burris TE, Baker PC, Ayer CT, et al. Flattening of central corneal curvature with intrastromal corneal 
rings of increasing thickness: an eye-bank eye study. J Cataract Refract Surg. 1993;19:182-7.

10. Daxer A, Fratzl P. Collagen orientation in the human corneal stroma and its implication in keratoconus. Invest Ophthalmol Vis Sci. 1997;38:121-9.

11. Albertazzi R. Tratamiento del queratocono con segmentos intracorneales. In: Albertazzi R, editor. Queratocono: pautas para su diagnóstico y tratamiento. Buenos Aires: Ediciones cientificas argentina para la keratoconussociety; 2010. p. 205-68.

12. Daxer A. Biomechanics of corneal ring implants. Cornea. 2015;34:1493-8.

13. Peña-García P, Alió JL, Vega-Estrada A, et al. Internal, corneal and refractive astigmatism as prognostic factor for ICRS implantation in mild to moderate keratoconus. J Cataract Refract Surg. 2014;40:1633-44.

14. Giacomin NT, Mello GR, Medeiros CS, Kiliç A, Serpe CC, Almeida HG, Kara-Junior N, Santhiago MR. Intracorneal ring segments implantation for corneal ectasia. J Refract Surg. 2016;32(12):829-39.

15. Piñero DP, Alio JL. Intracorneal ring segments in ectatic corneal disease-a review. Clin Exp Ophthalmol. 2010;38(2):154-67.

16. Colin J, Cochener B, Savary G, Malet F. Correcting keratoconus with intracorneal rings. J Cataract Refract Surg. 2000;26:1117-22.

17. Ertan A, Colin J. Intracorneal rings for keratoconus and keratectasia. J Cataract Refract Surg. 2007;33:1303-14.

18. Ertan A, Ozkilic E. Effect of age on outcomes in patients with keratoconus treated by Intacs using a femtosecond laser. J Refract Surg. 2008;24:690-5.

19. Ertan A, Kamburoglu G. Intacs implantation using femtosecond laser for management of keratoconus: comparison of 306 cases in different stages. J Cataract Refract Surg. 2008;34:1521-6.

20. Shabayek MH, Alió JL. Intrastromal corneal ring segment implantation by femtosecond laser for keratoconus correction. Ophthalmology. 2007;114: 1643-52.

21. Ertan A, Kamburoglu G, Bahadir M. Intacs insertion with the femtosecond laser for the management of keratoconus. One-year results. J Cataract Refract Surg. 2006;32:2039-42.

22. Ertan A, Bahadir M. Intrastromal ring segment insertion using a femtosecond laser to correct pellucid marginal corneal degeneration. J Cataract Refract Surg. 2006;32:1710-6.
23. Gatzioufas Z, Khine A, Elalfy E, Guber I, McLintock C, Sabatino F, Hamada S, Lake D. Clinical outcomes after keraring implantation for keratoconus management in patients older than 40 years: a retrospective, interventional cohort study. OphthalmolTher. 2018;7: 95-100.

24. Zare MA, Hashemi H, Salari MR. Intracorneal ring segment implantation for the management of keratoconus: safety and efficacy. J Cataract Refract Surg. 2007;33:1886-91.

25. Kymionis GD, Siganos CS, Tsiklis NS, et al. Longterm follow-up of Intacs in keratoconus. Am J Ophthalmol. 2007;143:236-44.

26. Alió JL, Shabayek MH, Artola A. Intracorneal ring segments for keratoconus correction: long-term follow-up. J Cataract Refract Surg. 2006;32:978-85.

27. Alió JL, Shabayek MH, Belda JI, Correas P, Diez Feijoo E. Analysis of results related to good and bad outcomes of Intacs implantation for keratoconus correction. J Cataract Refract Surg. 2006;32:756-61.

28. Colin J. European clinical evaluation: use of Intacs for the treatment of keratoconus. J Cataract Refract Surg. 2006;32:747-55.

29. Kanellopoulos AJ, Pe LH, Perry HD, Donnenfeld ED. Modified intracorneal ring segment implantations (Intacs) for the management of moderate to advanced keratoconus. Efficacy and complications. Cornea. 2006;25:29-33.

30. Hellstedt T, Mäkelä J, Uusitalo R, Emre S, Uusitalo R. Treating keratoconus with Intacs corneal ring segments. J Refract Surg. 2005;21:236-46.

31. Kwitko S, Severo NS. Ferrara intracorneal ring segments for keratoconus. J Cataract Refract Surg. 2004;30:812-20.

32. Miranda D, Sartori M, Francesconi C, Allemann N, Ferrara P, Campos M. Ferrara intrastromal corneal ring segments for severe keratoconus. J Refract Surg. 2003;19:645-53.

33. Siganos CS, Kymionis GD, Kartakis N, Theodorakis MA, Astyrakakis N, Pallikaris IG. Management of keratoconus with Intacs. Am J Ophthalmol. 2003;135:64-70.

34. Boxer Wachler BS, Chandra NS, Chou B, Korn TS, Nepomuceno R, Christie JP. Intacs for keratoconus. Ophthalmology. 2003;110:1031-40.

35. Ruckhofer J, Stoiber J, Twa MD, Grabner G. Correction of astigmatism with short arc-length intrastromal corneal ring segments. Ophthalmology. 2003;110:516-24. 
36. Ertan A, Bahadir M. Management of superior pellucid marginal degeneration with a single intracorneal ring segment using femtosecond laser. J Refract Surg. 2007;23:205-8.

37. Mularoni A, Torreggiani A, Di Biase A, Laffi GL, Tassinari G. Conservative treatment of early and moderate pellucid marginal degeneration: a new refractive approach with intracorneal rings. Ophthalmology. 2005;112:660-6.

38. Barbara A, Shehadeh-Mashaour R, Zvi R, Garzozi HJ. Management of pellucid marginal degeneration with intracorneal ring segments. J Refract Surg. $2005 ; 21: 296-8$.

39. Akaishi L, Tzelikis PF, Raber IM. Ferrara intracorneal ring implantation and cataract surgery for the correction of pellucid marginal corneal degeneration. J Cataract Refract Surg. 2004;30:2427-30.

40. Kymionis GD, Aslanides IM, Siganos CS, Pallikaris IG. Intacs for early pellucid marginal degeneration. J Cataract Refract Surg. 2004;30:230-3.

41. Rodriguez-Prats J, Galal A, Garcia-Lledo M, De la Hoz F, Alió JL. Intracorneal rings for the correction of pellucid marginal degeneration. J Cataract Refract Surg. 2003;29:1421-4.

42. Polkroy R, Levinger S, Hirsh A. Single Intacs segment for post-laser in situ keratomileusis keratectasia. J Cataract Refract Surg. 2004;30:1685-95.

43. Güell JL, Velasco F, Sánchez SI, Gris O, García-Rojas M. Intracorneal ring segments after laser in situ keratomileusis. J Refract Surg. 2004;20:349-55.

44. Alió JL, Artola A, Hassanein A, Haroun H, Galal A. One or 2 Intacs segments for the correction of keratoconus. J Cataract Refract Surg. 2005;31:943-53.

45. Carrasquillo KG, Rand J, Talamo JH. Intacs for keratoconus and post-LASIK ectasia: mechanical versus femtosecond laser-assisted channel creation. Cornea. 2007;26:956-62.

46. Rabinowitz YS, Li X, Ignacio TS, Maguen E. Intacs inserts using the femtosecond laser compared to the mechanical spreader in the treatment of keratoconus. J Refract Surg. 2006;22:764-71.

47. Kymionis GD, Siganos CS, Kounis G, Astyrakakis N, Kalyvianaki MI, Pallikaris IG. Management of postLASIK corneal ectasia with Intacs inserts. One-year results. Arch Ophthalmol. 2003;121:322-6.

48. Vega-Estrada A, Alió JL. The use of intracorneal ring segments in keratoconus. Eye Vis. 2016;3:8.
49. Shetty R, Kurian M, Anand D, Mhaske P, Narayana $\mathrm{KM}$, Shetty BK. Intacs in advanced keratoconus. Cornea. 2008;27:1022-9.

50. Chan CC, Sharma M, Wachler BS. Effect of inferiorsegment Intacs with and without C3-R on keratoconus. J Cataract Refract Surg. 2007;33:75-80.

51. Colin J, Cochener B, Savary G, Malet F, HolmesHiggin D. Intacs inserts for treating keratoconus. One year results. Ophthalmology. 2001;108:1409_ 14.

52. Alfonso JF, Lisa C, Merayo-Lloves J, Fernández-Vega Cueto L, Montés-Micó R. Intrastromal corneal ring segment implantation in paracentral keratoconus with coincident topographic and coma axis. J Cataract Refract Surg. 2012;38(9):1576-82.

53. Peña-García P, Alió JL, Vega-Estrada A, Barraquer RI. Internal, corneal, and refractive astigmatism as prognostic factors for intrastromal corneal ring segment implantation in mild to moderate keratoconus. J Cataract Refract Surg. 2014;40(10):163344 .

54. Sharma M, Wachler BSB. Comparison of single segment and double-segment Intacs for keratoconus and post-LASIK ectasia. Am J Ophthalmol. 2006;141:891-5.

55. Coskunseven E, Kymionis GD, Tsiklis NS, et al. Oneyear results of intrastromal corneal ring segment implantation (KeraRing) using femtosecond laser in patients with keratoconus. Am J Ophthalmol. 2008;145:775-9.

56. Siganos D, Ferrara P, Chatzinikolas K, Bessis N, Papastergiou G. Ferrara intrastromal corneal rings for the correction of keratoconus. J Cataract Refract Surg. 2002;28:1947-51.

57. Colin J, Malet FJ. Intacs for the correction of keratoconus: two-year follow-up. J Cataract Refract Surg. 2007;33(1):69-74.

58. Silvestrini TA, Mathis ML, Loomas BE, Burris TE. A geometric model to predict the change in corneal curvature from the intrastromal corneal ring (ICR). Investig Ophthalmol Vis Sci. 1994;35:2023.

59. Kaya V, Utine CA, Karakus SH, Kavadarli I, Yilmaz OF. Refractive and visual outcomes after Intacs vs ferrara intrastromal corneal ring segment implantation for keratoconus: a comparative study. J Refract Surg. 2011;27(12):907-12.

60. Gatzioufas Z, Panos GD, Elalfy M, Khine A, Hamada S, Lake D, Kozeis N, Balidis M. Effect of conus eccentricity on visual outcomes after intracorneal ring segments implantation in keratoconus. J Refract Surg. 2018;34(3):196-200. 
61. Vega-Estrada A, Alio JL, Brenner LF, Javaloy J, Plaza Puche AB, Barraquer RI, et al. Outcome analysis of intracorneal ring segments for the treatment of keratoconus based on visual, refractive, and aberrometric impairment. Am J Ophthalmol. 2013;155(3):575-84.

62. Vega-Estrada A, Alió JL, Brenner LF, Burguera N. Outcomes of intrastromal corneal ring segments for treatment of keratoconus: five-year follow-up analysis. J Cataract Refract Surg. 2013;39:1234-40.

63. Rabinowitz Yaron S. INTACS for keratoconus and ectasia after LASIK. Int Ophthalmol Clin. 2013;53(1):27-39.

64. Niknam S, Shamshiri M, Shahrzad SS, Alipour A, Rajabi MB, Rajabi MT. Treatment of moderate to severe keratoconus with 6-mm Intacs SK. Int J Ophthalmol. 2012;5(4):513-6.

65. Abad JC, Arango J, Tobon C. Comparison of astigmatism correction using shorter arc length $90^{\circ} / 120^{\circ}$ asymmetric intacs severe keratoconus versus $150^{\circ}$ single-segment intacs severe keratoconus in asymmetric keratoconus. Cornea. 2011;30(11):1201-6.

66. Levinger S, Pokroy R. Keratoconus managed with Intacs: one-year results. Arch Ophthalmol. 2005;123(10):1308-14.

67. Ertan A, Kamburoğlu G, Akgón U. Comparison of outcomes of 2 channel sizes for intrastromal ring segment implantation with a femtosecond laser in eyes with keratoconus. J Cataract Refract Surg. 2007;33(4):648-53.

68. Alió JL, Piñero DP, Alesón A, Teus MA, Barraquer RI, Murta J, et al. Keratoconus-integrated characterization considering anterior corneal aberrations, internal astigmatism, and corneal biomechanics. J Cataract Refract Surg. 2011;37:552-68.

69. Kymionis GD, Tsiklis NS, Pallikaris AI, et al. Longterm follow-up of Intacs for post-LASIK corneal ectasia. Ophthalmology. 2006;113:1909-17.

70. Torquetti L, Berbel RF, Ferrara P. Long-term followup of intrastromal corneal ring segments in keratoconus. J Cataract Refract Surg. 2009;35(10): 1768-73.

71. Pipero DP, Ali $\sigma$ JL, El Kady B, Pascual I. Intracorneal ring segment implantation in corneas with postlaser in situ keratomileusis keratectasia. J Cataract Refract Surg. 2010;36(1):102-9.

72. Pipero DP, Alio JL, El Kady B, Coskunseven E, Morbelli H, Uceda-Montanes A, Maldonado MJ, Cuevas D, Pascual I. Refractive and aberrometric outcomes of intracorneal ring segments for keratoconus: mechanical versus femtosecond-assisted procedures. Ophthalmology. 2009;116(9):1675-87.

73. Kymionis GD, Grentzelos MA, Diakonis VF, Pallikaris AI, Pallikaris IG. Nine-year follow-up of intacs implantation for keratoconus. Open Ophthalmol J. 2009;3:77-81.

74. Vega-Estrada A, Alió JL, Plaza-Puche AB. Keratoconus progression after intrastromal corneal ring segment implantation in young patients: Five-year follow-up. J Cataract Refract Surg. 2015;41(6):114552.

75. Saelens IE, Bartels MC, Bleyen I, Van Rij G. Refractive, topographic, and visual outcomes of same-day corneal cross-linking with Ferrara intracorneal ring segments in patients with progressive keratoconus. Cornea. 2011;30:1406-8.

76. Kılıç A, Kamburoglu G, Akıncı A. Riboflavin injection into the corneal channel for combined collagen crosslinking and intrastromal corneal ring segment implantation. J Cataract Refract Surg. 2012;38:878-83.

77. Alió JL, Artola A, Ruiz-Moreno JM, et al. Changes in keratoconic corneas after intracorneal ring segment explantation and reimplantation. Ophthalmology. 2004;111:747-51.

78. Ferrer C, Alio IJMA, et al. Causes of intrastromal corneal ring segment explantation: clinicopathologic correlation analysis. J Cataract Refract Surg. 2010;36(6):970-7.

79. Coskunseven E, Kymionis G, Tsiklis N, Arslan S, Siganos C, Jankov M, Pallikaris I. Complications of intrastromal corneal ring segment implantation using a femtosecond laser for channel creation: a survey of 850 eyes with keratoconus. Acta Ophthalmol. 2011;89:54-7.

80. Giacomin NT, Mello GR, Medeiros CS, Kiliç A, Serpe CC, Almeida HG, Kara-Junior N, Santhiago MR. Intracorneal ring segments implantation for corneal ectasia. J Refract Surg. 2016;32(12):829-39.

81. Yeung SN, Lichtinger A, Ku JYF, Kim P, Low SAW, Rootman DS. Intracorneal ring segment explantation after intracorneal ring segment implantation combined with same-day corneal collagen crosslinking in keratoconus. Cornea. 2013;32: 1617-20.

82. Flecha-Lescún J, Calvo B, Zurita J, Ariza-Gracia MÁ. Template-based methodology for the simulation of intracorneal segment ring implantation in human corneas. Biomech Model Mechanobiol. 2018;17(4): 923-38. 